\title{
Differential cardiac effects of aerobic interval training versus moderate continuous training in a patient with schizophrenia: a case report
}

\author{
Marco Herbsleb ${ }^{1,2}$, Tobias Mühlhaus ${ }^{1}$ and Karl-Jürgen Bär ${ }^{1}{ }^{*}$ \\ 1 Pain and Autonomic Integrative Research (PAIR), Department of Psychiatry and Psychotherapy, University Hospital Jena, Jena, Germany \\ ${ }^{2}$ Clinical Exercise Physiology (CEP), Department of Sports Medicine and Health Promotion, Friedrich-Schiller-University, Jena, Germany
}

Edited by:

Einar Vedul-Kjelsås, Norwegian

University of Science and Technology,

Norway

Reviewed by:

Jan Hoff, Norwegian University of Science and Technology, Norway

Ole Kemi, University of Glasgow, UK

*Correspondence:

Karl-Jürgen Bär, Department of

Psychiatry and Psychotherapy,

University Hospital Jena,

Philosophenweg 3, Jena 07743,

Germany

e-mail:karl-juergen.baer@

med.uni-jena.de
Increased cardiovascular morbidity and mortality rates for patients with schizophrenia are reported to contribute to their reduced life expectancy. Common reasons for increased cardiac mortality rates include cigarette smoking, obesity, dyslipidemia, diabetes, and poorer health behavior in general. The majority of excess mortality among people with schizophrenia is caused by cardiovascular complications. Reduced vagal activity might be one important mechanism leading to this increased cardiac mortality and has been consistently described in patients and their healthy first-degree relatives. In this case study, we compared two different aerobic exercise regimes in one patient with chronic schizophrenia to investigate their effects on cardiovascular regulation. The patient completed a 6-week period of moderate continuous training (CT) followed by a 6-week period of interval training (IT), each regime two times per week, on a stationary bicycle. This was followed by a 6-week period of detraining. Primary outcome measures examined heart rate (HR) and heart rate variability (HRV) at rest while secondary measures assessed fitness parameters such as the ventilatory threshold $1\left(\mathrm{VT}_{1}\right)$. We observed that IT was far more effective than moderate $\mathrm{CT}$ in increasing $\mathrm{HRV}$, as indicated by root mean of squared successive difference (improvement to baseline 27 versus 18\%), and reducing resting HR (-14 versus $0 \%$ ). Improvement in $\mathrm{VT}_{1}$ (21 versus -1\%) was only observed after IT. Our study provides preliminary data that the type of intervention is highly influential for improving cardiac function in patients with schizophrenia. While cardiovascular function might be influenced by CT to some degree, no such effect was present in this patient with schizophrenia. In addition, the beneficial effect of IT on HR regulation vanished completely after a very short period of detraining after the intervention.

Keywords: schizophrenia, interval training, continuous training, heart rate variability, exercise intervention

\section{BACKGROUND}

Schizophrenia is associated with poor levels of physical health leading to high rates of physical morbidity and mortality (1-3). The relative risk of premature death of patients with schizophrenia is increased by two to fourfold and they are said to die at least 10 years earlier than their age-matched contemporaries (4). A biological predisposition, the illness itself (either through positive, negative, or cognitive symptoms) and an unhealthy lifestyle might contribute to excess mortality from natural causes. Interestingly, poor physical health occurs already at an early age in these patients, and those aged between 25 and 44 years seem to differ most pronouncedly from their age-matched contemporaries. Various studies have suggested increased prevalence and/or mortality rates of some diseases such as diabetes, hypertension, heart disease, gastrointestinal or respiratory disorder, and breast cancer (3-8). However, although risk-factors such as increased weight, smoking rates, poor diet, and activity levels have a critical role in increased risk of morbidity and mortality, they do not account for the entire hazard (9). There seems to be some disease-inherent biological predisposition. The majority of excess mortality among people with schizophrenia is caused by cardiovascular complications, especially coronary heart disease (9). In addition, the prevalence of heart failure or arrhythmia is increased in this population (10). Reduced vagal activity might be one important mechanism leading to this increased cardiac mortality (11) and has been consistently described in patients and their healthy first-degree relatives (12-14). This autonomic imbalance has been investigated by means of heart rate variability (HRV) and complexity studies. High HRV indicates healthy cardiovascular regulation and is suggestive of the ability to adjust to environmental changes. It is associated with long-term survival with respect to various heart conditions. In patients with schizophrenia, parasympathetic parameters of the time domain of HRV such as root mean of squared successive difference (RMSSD) and of the frequency domain such as HF (high frequency) have repeatedly indicated low parasympathetic (vagal) modulation and have been associated with low HRV (15). Similarly, the complexity measure compression entropy $(\mathrm{Hc})$, which reflects vagal modulation to some extent, has been shown to indicate reduced complexity in patients $(16,17)$. In addition, the relatively novel measure QT 
variability index (QTvi) indicating cardiac repolarization lability has been studied in the disease and results were suggestive of augmented sympathetic modulation and an increased risk of arrhythmias (18). Interestingly, most studies have reported an association of the autonomic imbalance with the degree of positive symptoms (i.e., delusions) correlating negatively with, e.g., RMSSD or the complexity measure Hc. Moreover, increased HRs have been associated with poor outcomes in schizophrenia, suggesting that heightened SNS activity is an important factor for progression of the disease. Not surprisingly, this abnormal pattern of cardiac regulation is not only present at rest but more importantly during exercise (19). The study by Ostermann et al. (19) showed reduced physical capacity, even after adjusting for weight, and as expected, decreased vagal modulation was associated with psychopathology and a pro-inflammatory response after exercise in patients. Likewise, Heggelund and colleagues showed that male patients suffering from schizophrenia have reduced $\mathrm{VO}_{2 \text { peak }}$ in comparison to the general population. The authors suggest that the assessment of $\mathrm{VO}_{2 \text { peak }}$ should be incorporated into clinical practice for cardiac risk prediction in these patients (20), especially since aerobic high-intensity training has been shown to improve $\mathrm{VO}_{2 \text { peak }}$ in patients with coronary artery disease (21), as well as in patients with schizophrenia (22). Similarly, a number of studies point to a significant improvement of schizophrenia symptoms via aerobic exercise $(23,24)$. This has also been confirmed by a first meta-analysis (25). However, the increased HR in these patients, which is not primarily associated with neuroleptic medication, has not specifically been addressed by exercise intervention studies.

It is well known that aerobic endurance training induces a reduction in heart rate (HR) at rest and during submaximal exercise intensities (26). Many previous studies have suggested that bradycardia due to exercise may be caused by decreased cardiac sympathetic modulation and increased cardiac parasympathetic modulation (27-30). Therefore, aerobic physical exercise has been proven to be an effective method to decrease HR at rest by increasing its variability (HRV) (31-33). Similarly, data underline this effect during submaximal exercise intensities $(34,35)$ and after recovery (36). The extent of cardiac effects after aerobic training seems to be related to training intensities and exercise regime (e.g., interval and continuous exercise) (37-39). One study by Helgerud et al. (40) showed that aerobic high-intensity interval training (IT) improved $\mathrm{VO}_{2 \max }$ more than moderate training in healthy college students (40). Interestingly, changes in $\mathrm{VO}_{2 \max }$ corresponded with changes in stroke volume of the heart, indicating a close link between the two measures.

Therefore, it is tempting to speculate that different training regimens might induce different effects on increased HRs and low vagal function in patients with schizophrenia. The purpose of this case study was therefore to explore differential effects on cardiovascular regulation and physical fitness of moderate continuous training (CT) for 6 weeks versus a 6-week period of IT in a female patient suffering from paranoid schizophrenia.

\section{CASE PRESENTATION}

A 54-year-old woman came initially to her psychiatrist with delusions of being observed, auditory hallucinations, and severe insomnia when she was 30 years of age. At the time, a diagnosis of paranoid schizophrenia according to ICD-9 criteria was made. First admission to our hospital occurred 8 years ago when she had various delusions, thoughts of references, auditory hallucinations, and overslept regularly. She was treated with risperidone ( $4 \mathrm{mg} /$ day), and her psychotic symptoms improved substantially. She had lost her job as a cleaning lady during the course of her disease and is married. Her childhood and development were unremarkable. Her medical history revealed a thyroidectomy in 1989 and T3 replacement. No further diseases are known. She experienced menopause at age 50 . Her mother's brother and sister both committed suicide. However, no data are available on whether underlying psychiatric conditions were known. After initial admission, she has been admitted to our hospital about once a year. Positive symptoms decreased over time and negative symptoms became aggravated. During the last admission, she complained mainly about a lack of energy, anhedonia, sleeping problems, and some urinary incontinence. She denied positive symptoms such as hallucinations and reported some delusions of persecution. She complained of an unspecific anxiety, low mood, lack of energy, and worry about the future. She is now treated with ziprasidone (blood level $0.17 \mu \mathrm{g} / \mathrm{ml}$ ). She has become obese during the last 5 years (BMI: 40.7) and very mildly incontinent. She has not done any physical exercise for about 20 years. No signs of diabetes, increased glucose levels, heart disease, or any other condition were detectable. Routine ECG and laboratory tests were entirely unremarkable. Her initial ratings on the positive and negative syndrome scale [PANNS; (41)] were: positive scale $=24$; negative scale $=42$; and general psychopathology 45 . She agreed to participate in an exercise intervention and gave written informed consent to a protocol approved by the Ethics Committee of the Medical Faculty of the Friedrich-Schiller-University, Jena.

\section{STUDY DESIGN}

The present study involved a total period of 18 weeks, which included a 6-week period of moderate CT followed by a 6-week period of IT and finally 6-weeks of detraining. Before and after each period, we performed a graded cardiopulmonary exercise test (CET) on a stationary bicycle in order to assess her physical fitness and the training effects on cardiac regulation (Figure 1). The patient was instructed to refrain from additional exercise outside of the study requirements as well as from alcohol and caffeine intake for at least $24 \mathrm{~h}$ prior to any of the test sessions.

\section{BASELINE AND OUTCOME MEASUREMENTS}

Three days in advance, and after each training period, the patient performed a CET on an electronically braked cycle ergometer (Ergometrics 900, Ergoline, Bitz, Germany). In addition, to avoid possible learning effects, an extra CET was performed the week before the first training period. The patient was weighed on a calibrated medical scale (Kern, Model MPD 250K, BalingenFrommern, Germany), wearing sportswear. Her height was measured using a Harpenden stadiometer (Holtain Ltd., Crosswell, Crymych, UK) to calculate BMI [mass $(\mathrm{kg}) /$ height $\left(\mathrm{m}^{2}\right)$ ]. Skinfold measurements were taken from the biceps, triceps, supra-illiac, and subscapular skinfold according to the published guidelines (42). Linear regression equations of Durnin and Womersley (43) were 


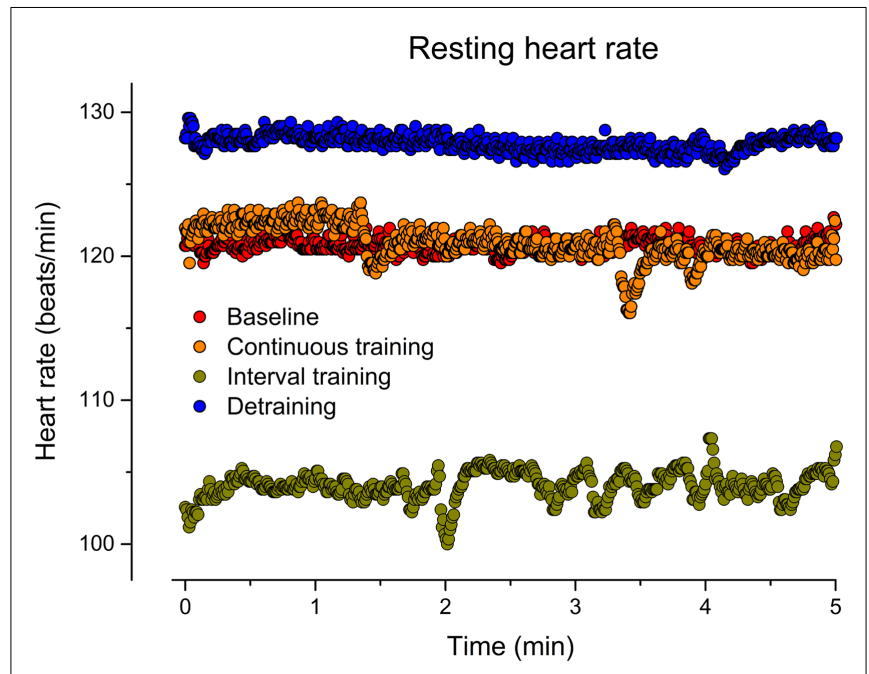

FIGURE 1 | Resting heart rate (beat-to-beat) before training (baseline), after $\mathbf{6}$ weeks of continuous training, $\mathbf{6}$ weeks of interval training, and 6 weeks of detraining.

used to predict body density. Percentage of body fat was estimated using the equation by Siri (44).The patient was then familiarized with the exercise testing equipment and procedures.

\section{Heart rate and heart rate variability measurements}

An electrocardiographic recording system (AMEDTEC ECGpro ${ }^{\circledR}$ CardioPart 12 USB, Aue, Germany) was used that meets specifications set by the American heart association (45). The ECG was obtained for $5 \mathrm{~min}$ while the patient rested quietly in a sitting position on the electronically braked cycle ergometer before each exercise test session. All measurements were taken at the same time of day (12:00 p.m., midday) in order to minimize circadian time effects. Prior to measurement, the patient rested comfortably for at least $15 \mathrm{~min}$ in a sitting position on a chair.

Signal processing. Heart rate time series consisting of successive beat-to-beat intervals (RR) were extracted from the raw data records. Afterwards, these time series were filtered by applying an adaptive variance estimation algorithm to remove and interpolate ventricular premature beats and artifacts (e.g., movement, electrode noise, and extraordinary peaks). The RR from the second up to the fourth minute was used for analysis. We obtained the baseline HR and the RMSSD as a time domain parameter of HRV. Non-linear properties of HR were investigated using the Poincaré plot. A return map was constructed by plotting each RR against the preceding RR. The variance of the resulting scattergram was characterized by the deviations SD1 and SD2. Here, we focused on the instantaneous variability reflected by SD1, which is related to parasympathetic activity (46). Because of a strong dependency of SD1 on basic heart rhythm we also estimated this index normalized by mean $\mathrm{RR}\left(\mathrm{SD} 1 / \mathrm{RR}_{\text {Mean }}\right)$ (47).

\section{Physical fitness assessment}

The resting period was followed by a 3-min pedaling session at $6 \mathrm{~W}$. Thereafter, CET was initiated from a baseline work rate of
$15 \mathrm{~W}$ and a ramp slope of $15 \mathrm{~W} / \mathrm{min}$ until the patient reached her limit of tolerance. Exhaustion occurred when the patient could not longer maintain the required power output. We verbally encouraged the patient to aim for a pedaling-frequency of 70-80 rpm and to give maximum effort until volitional exhaustion. HR and gas exchange measurements (MetaLyzer 3B; Cortex Biophysik, Leipzig, Germany; breath-by-breath system) were carried out throughout the test. The respiratory exchange ratio (RER) of carbon dioxide $\left(\mathrm{CO}_{2}\right)$ output to oxygen $\left(\mathrm{O}_{2}\right)$ uptake served as an objective control parameter for the degree of effort.

For data analysis, the breath-by-breath values were smoothed using a 15-breath moving average, aligned to the time of the central breath (48). Peak oxygen uptake $\left(\mathrm{VO}_{2}\right.$ peak), peak minute ventilation (VEpeak), and peak RER (RERpeak) were defined as the highest value of 15-breath average occurring during CET. The highest HR detected during CET was defined as HRpeak. The peak power output (Ppeak) was defined as the highest power output that was sustained for 1 min during the test. When the patient was not able to cycle to the end of the last 1-min interval, Ppeak was linearly interpolated based on the proportion of the time completed during the final stage.

For the description of aerobic capacity, the ventilatory threshold $1\left(\mathrm{VT}_{1}\right)$, a common and reproducible submaximal indicator of endurance capacity, was chosen. $\mathrm{VT}_{1}$ was determined using a combined model including the following three methods: (i) the $\mathrm{V}$-slope method (49): the first disproportionate increase in $\mathrm{VCO}_{2}$ determined from the $\mathrm{VCO}_{2}-\mathrm{VO}_{2}$ plot, (ii) the ventilatory equivalent method: an increase in $\mathrm{VE} / \mathrm{VO}_{2}$ with no increase in $\mathrm{VE} / \mathrm{VCO}_{2}$, and (iii) the excess carbon dioxide method: an increase from steady state to an excess production of $\mathrm{CO}_{2}$.

\section{Training program}

The patient trained twice a week (Tuesday and Friday) under supervision of an exercise physiologist. Each training session lasted 35 min including a standard warm-up (5 min) and cool-down ( $5 \mathrm{~min}$ ). Training intensity was prescribed in relation to the power output corresponding to the $\mathrm{VT}_{1}$ and the $\mathrm{VO}_{2}$ peak obtained in the respective preceding incremental exercise test. The warm-up and the cool-down periods were performed at power output of 70 and $40 \%$ of the $\mathrm{VO}_{2}$ at $\mathrm{VT}_{1}$, respectively. $\mathrm{HR}$ was continuously recorded throughout each training session using a HR monitor (RS800CX, Polar Electro, Kempele, Finland) and the Borg 6-20 scale was used to assess the rate of perceived exertion during each training session.

The moderate-intensity training (CT) consisted of $25 \mathrm{~min}$ of continuous exercise at a power output, which corresponds to $20 \%$ of the difference between the $\mathrm{VT}_{1}$ and $\mathrm{VO}_{2}$ peak $(20 \%)$, whereas the IT session consisted of $25 \mathrm{~s} \times 30 \mathrm{~s}$ bursts at $80 \%$ with $30 \mathrm{~s}$ active recovery (a work to rest ratio of $1: 1$ ). During the $30-\mathrm{s}$ recovery between bursts, the patient pedaled at a power output of $10 \mathrm{~W}$. The exercise prescription of CT and IT was designed to apply different intensities. However, the same overall training load for each training session was achieved for the patient. The total amount of work (Watt $\times$ min) for the CT $(62 \mathrm{~W} \times 25 \mathrm{~min})$ and IT $[(111 \mathrm{~W} \times 12.5 \mathrm{~min})+(10 \mathrm{~W} \times 12.5 \mathrm{~min})]$ conditions were $1555 \mathrm{~W} \times \min$ and $1517 \mathrm{~W} \times \mathrm{min}$, respectively. The resulting 
energy expenditure (EE) during CT (332 kcal) and IT (331 kcal) training sessions were comparable. The EE can be estimated using the American College of Sports Medicine's metabolic calculation formula for leg cycling $\left[\mathrm{VO}_{2}=\left(10.8 \times\right.\right.$ Watt $\times$ body mass $\left.\left.{ }^{-1}\right)+7\right]$. The estimated training $\mathrm{VO}_{2}(1 / \mathrm{min})$ can then converted into $\mathrm{EE}$ ( $\mathrm{kcal} / \mathrm{min}$ ) by multiplying by $5 \times$ total number of cycling minutes.

\section{RESULTS}

No significant change of PANNS rating was observed although the patient indicated some subjective improvements. Compliance of the patient with training requirements was excellent and without differences between CT and IT, although the IT was subjectively slightly more strenuous for the patient than the CT program (Borg: $16.8 \pm 1.4$ for the CT versus $18.3 \pm 0.7$ for the IT). Average HR during training was $141 \pm 4 \mathrm{bpm}$ in the CT (range 134-148 bpm) and $141 \pm 5 \mathrm{bpm}$ in the IT (131-149 bpm), respectively. The patient maintained almost constant body fat, whereas body mass went slightly down during the training period and increased after detraining (Table 1).

\section{Heart rate and heart rate variability}

As indicated in Figure 1, CT for 6 weeks did not affect the resting HR in our patient (mean HR: 121) in comparison to baseline (mean HR: 121). In contrast, IT for 6 weeks reduced the resting HR by about 14\% (mean HR: 104). After discontinuation of training, the resting HR returned to the initial increased level (mean HR: 128). Figure 2 illustrates HRs during the CET at baseline, after CT, after IT, and after 6 weeks of detraining. Only the IT induced a pronounced effect on resting HR during exercise, which was lost after 6 weeks of detraining.

Similarly, HRV indices reflected changes in autonomic regulation. IT was far more effective than moderate CT to increase HRV. Changes of HRV measures such as RMSSD, SD1, and $\mathrm{SD} 1 / \mathrm{RR}_{\text {Mean }}$ are depicted in Figure 3. In particular, RMSSD showed an improvement to baseline after CT by $18 \%$ while IT led to $27 \%$ improvement. Similarly, SD1 increased after CT by 18 versus $27 \%$ after IT. Most pronounced was the effect when SD1

Table 1 | Anthropometric characteristics and maximal ergometric values of the patient before training, after 6 -weeks continuous training, 6-weeks interval training, and a detraining of 6 weeks.

\begin{tabular}{lcccc}
\hline & Baseline & $\begin{array}{l}\text { Continuous } \\
\text { training }\end{array}$ & $\begin{array}{l}\text { Interval } \\
\text { training }\end{array}$ & Detraining \\
\hline Body mass (kg) & 106.8 & 104.6 & 103.0 & 104.5 \\
Body mass index $\left(\mathrm{kg} / \mathrm{m}^{2}\right)$ & 40.7 & 39.9 & 39.2 & 39.8 \\
Body fat (\%) & 46.6 & 46.1 & 46.3 & 46.7 \\
HRpeak (beats/min) & 146 & 153 & 152 & 154 \\
Ppeak (W) & 105 & 128 & 143 & 120 \\
VO ${ }_{2}$ peak (ml/kg/min) & 15.7 & 17.0 & 19.1 & 17.2 \\
VEpeak (I/min) & 42.5 & 49.3 & 55.5 & 51.4 \\
RERpeak & 1.06 & 1.18 & 1.14 & 1.12 \\
\end{tabular}

HRpeak, peak heart rate; Ppeak, peak power output; VO ${ }_{2}$ peak, peak oxygen uptake; VEpeak, peak minute ventilation; RERpeak, peak respiratory exchange ratio. was adjusted to HR. Here, $18 \%$ after CT and $48 \%$ after IT were observed. All HRV measures returned to baseline levels within 6 weeks after detraining (Figure 3).

\section{Changes of physical fitness}

As displayed in Figure 4, we did not observe a change of $\mathrm{VT}_{1}$ after CT when comparing baseline and fitness after training $(-1 \%)$. Only a slight increase was observed as indicated by $\mathrm{VO}_{2}$ peak $(8 \%$ improvement) after CT. In contrast, after IT, a $21 \%$ increase was observed for $\mathrm{VT}_{1}$ and $22 \%$ for $\mathrm{VO}_{2}$ peak.
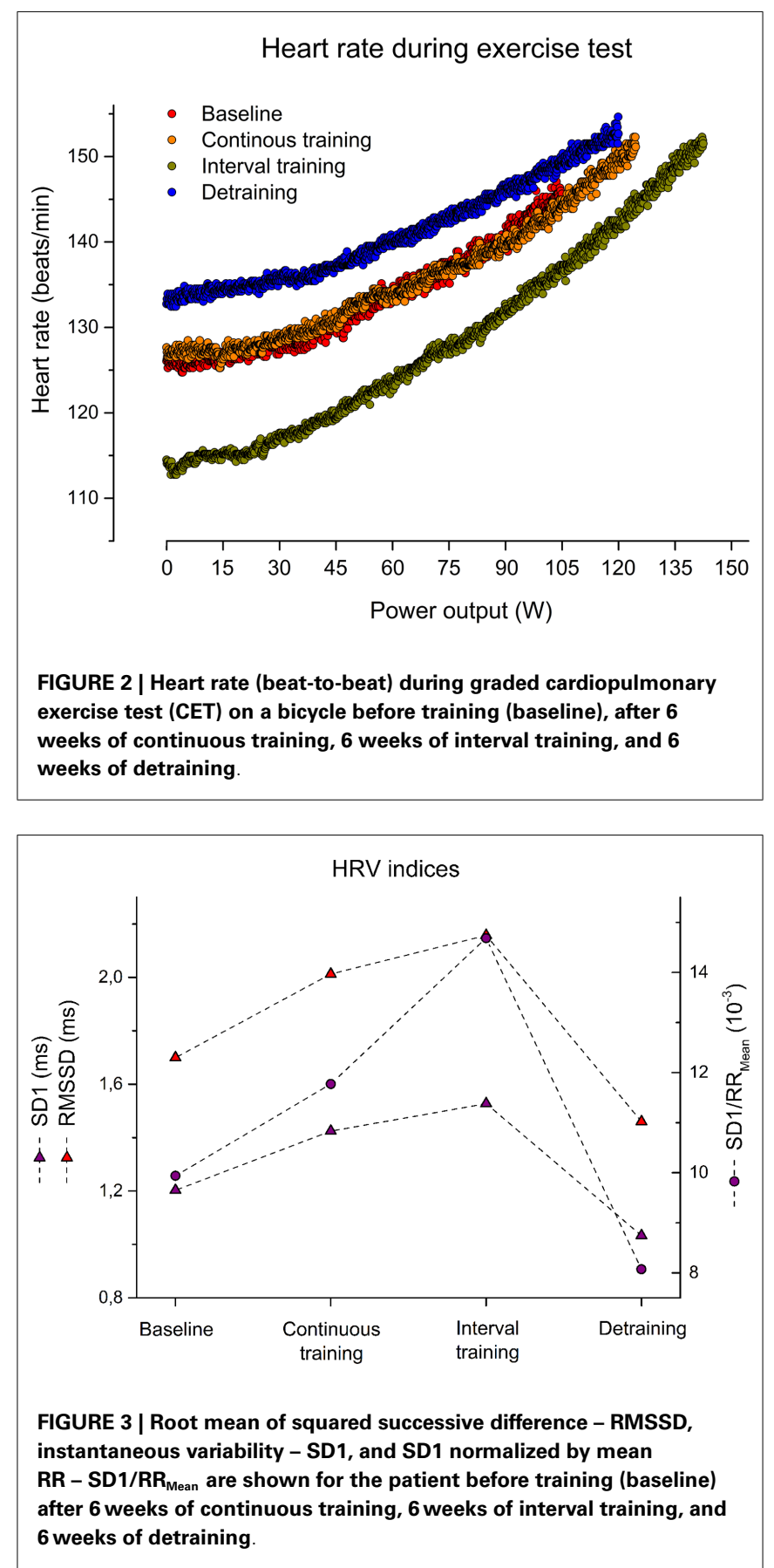


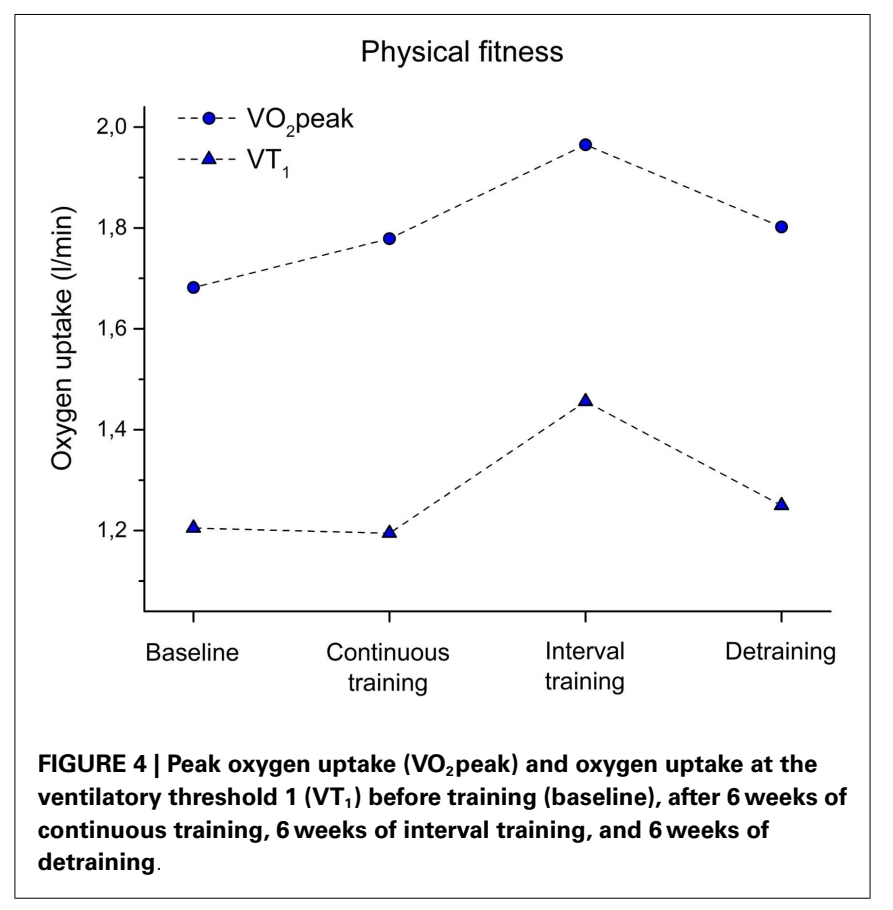

\section{DISCUSSION}

Low cardiorespiratory fitness has been recognized as a strong and independent risk-factor for all-cause mortality in adults and a key risk-factor for coronary heart disease-related mortality (50-52). Reduced physical fitness has been reported in first-episode schizophrenia patients, as well as in more chronic patients $(20,53,54)$. Research on exercise frequency and schizophrenia indicates that patients spend less time engaged in regular physical activity than the general population $(55,56)$. The health effects of regular physical activity are well established and include decreased mortality and morbidity related to cardiovascular disease and diabetes, as well as improvements in mental health, physical functioning, and body weight (57). However, the specific autonomic dysregulation in patients with schizophrenia might require particular physical interventions. Here, we present a case showing that a 6-week continuous exercise intervention neither altered cardiovascular regulation nor physical fitness. Although we have observed this in only one subject, we believe it is worth discussing to generate hypotheses for future interventional studies. Previous research suggested that continuous aerobic physical exercise is an effective method to increase physical fitness (i.e., peak oxygen uptake) and to decrease $\mathrm{HR}$ at rest by increasing its variability (HRV) (31). Moreover, previous studies by Rognmo et al. (21) and Helgerud et al. (40) emphasized the superiority of high-intensity training for $\mathrm{VO}_{2 \max }$ and $\mathrm{VO}_{2 \text { peak }}$ in comparison to moderate-intensity exercise $(21,40)$. Similar effects were observed in our patient, including an increase of $\mathrm{VO}_{2 \text { peak }}$ of $22 \%$ resulting from high-intensity training, in contrast to only $8 \%$ from CT. However, the study by Helgerud et al. (40) showed an influence of CT on HR while studying running economy in healthy subjects (40). No such effect of CT on HR was observed in our patient, even though she was completely sedentary before the exercise intervention started. The exercise physiologist who observed the training sessions and HR assessments confirmed that the correct amount of exercise was performed. In contrast, IT sessions, combining high-intensity bursts power output with low intensity recovery phases, revealed a significant effect both on cardiovascular regulation and physical fitness. It might indicate that patients with schizophrenia require a specific training program. It is well known that patients with schizophrenia suffer from a high internal stress level. It is likely that continuous exercise is an additional stressor for these patients, which might not yield the desired effect. However, IT consists of short bursts of physical strain followed by relaxation. Thus, the cardiovascular system of patients challenged in this fashion might respond more readily in comparison to continuous exercise for $30 \mathrm{~min}$. Interestingly, yoga contains also an alternating stress-relaxation sequence. Duraiswamy et al. (58) showed that yoga had superior efficiency in comparison to exercise training (58). Similarly, a recent review of randomized control trials showed that yoga therapy might serve as a useful add-on treatment to reduce general psychopathology and positive and negative symptoms (59). Although yoga methods might differ enormously, it is thought to create inner, physical, and emotional balance through the use of body postures (called asanas) combined with breathing techniques (pranayama). This is of particular interest since breathing rates and rhythms are altered in the disease $(17,60)$. An alternative interpretation of our results could be that titration of exercise amount (volume and/or intensity) to elevated levels over a period of 12 weeks by changing from CT to IT increasing the amount halfway through produced beneficial effects. One might speculate that this was achieved by motivationally or otherwise enabling the subject to perform vigorous exercise after a 6week run-in period of more moderate exercise. Future studies need to take this possibility into account to adequately calculate run-in periods and training durations for patients with schizophrenia.

In addition, it is important to realize how quickly HR and physical fitness improvement vanished after the intervention. Mean resting HR was in fact slightly increased in comparison to baseline (7 beats/min) after detraining. After such a long time of training, our patient was well accustomed to our laboratory and to the stuff. Thus, we can rather exclude major problems during adjustment. In addition, disease severity remained stable. Therefore, it is important to include post-training examinations in future studies to observe the stability of gained cardiovascular effects.

Our results are limited due to the presentation of a single case only. Additionally, the order of CT and IT might have influenced the better response to IT. Possibly, the 6 weeks CT training prepared the ground for the IT response. Therefore, randomized control trials are needed to investigate different exercise intervention schedules to understand physiological responses in these patients. Endurance training should be compared with IT or a combination of relaxation techniques and endurance training. This might help to change the physiological state. It is especially of great importance since psychiatrists tend to focus on changes of brain structure and function and thereby sometimes overlook physiological responses. However, we believe that physiological effects need to be included to estimate increased cardiovascular health in these patients. This is especially important since effects vanished so quickly. 


\section{CONCLUDING REMARIS}

Our case illustrates the need for comparing different exercise interventions in patients with schizophrenia, since cardiovascular dysfunction might interfere with training adaptations of the body normally observed. Although randomized control trials are mandatory for an evaluation of exercise interventions, our case illustrates that the physiological basis needs to be evaluated before effects of exercise on brain function and structure are analyzed in these patients.

\section{ACKNOWLEDGMENTS}

We thank Birgit Dorschner for her assistance during the exercise intervention.

\section{REFERENCES}

1. Mitchell AJ, Malone D. Physical health and schizophrenia. Curr Opin Psychiatry (2006) 19:432-7. doi:10.1097/01.yco.0000228767.71473.9e

2. von Hausswolff-Juhlin Y, Bjartveit M, Lindstrom E, Jones P. Schizophrenia and physical health problems. Acta Psychiatr Scand Suppl (2009) 438:15-21. doi:10.1111/j.1600-0447.2008.01309.x

3. Smith DJ, Langan J, Mclean G, Guthrie B, Mercer SW. Schizophrenia is associated with excess multiple physical-health comorbidities but low levels of recorded cardiovascular disease in primary care: cross-sectional study. BMJ Open (2013) 3:e002808. doi:10.1136/bmjopen-2013-002808

4. Brown S. Excess mortality of schizophrenia. A meta-analysis. Br J Psychiatry (1997) 171:502-8. doi:10.1192/bjp.171.6.502

5. Brown S, Inskip H, Barraclough B. Causes of the excess mortality of schizophrenia. Br J Psychiatry (2000) 177:212-7. doi:10.1192/bjp.177.3.212

6. Carney CP, Jones L, Woolson RF. Medical comorbidity in women and men with schizophrenia: a population-based controlled study. J Gen Intern Med (2006) 21:1133-7. doi:10.1111/j.1525-1497.2006.00563.x

7. Saha S, Chant D, Mcgrath J. A systematic review of mortality in schizophrenia: is the differential mortality gap worsening over time? Arch Gen Psychiatry (2007) 64:1123-31. doi:10.1001/archpsyc.64.10.1123

8. Weber NS, Cowan DN, Millikan AM, Niebuhr DW. Psychiatric and general medical conditions comorbid with schizophrenia in the national hospital discharge survey. Psychiatr Serv (2009) 60:1059-67. doi:10.1176/appi.ps.60.8.1059

9. Joukamaa M, Heliovaara M, Knekt P, Aromaa A, Raitasalo R, Lehtinen V. Schizophrenia, neuroleptic medication and mortality. Br J Psychiatry (2006) 188:122-7. doi:10.1192/bjp.188.2.122

10. Curkendall SM, Mo J, Glasser DB, Rose Stang M, Jones JK. Cardiovascular disease in patients with schizophrenia in Saskatchewan, Canada. J Clin Psychiatry (2004) 65:715-20. doi:10.4088/JCP.v65n0519

11. Koponen H, Alaraisanen A, Saari K, Pelkonen O, Huikuri H, Raatikainen MJ, et al. Schizophrenia and sudden cardiac death: a review. Nord J Psychiatry (2008) 62:342-5. doi:10.1080/08039480801959323

12. Bär KJ, Boettger MK, Berger S, Baier V, Sauer H, Yeragani VK, et al. Decreased baroreflex sensitivity in acute schizophrenia. J Appl Physiol (1985) (2007) 102:1051-6. doi:10.1152/japplphysiol.00811.2006

13. Bär KJ, Berger S, Metzner M, Böttger MK, Schulz S, Ramachandraiah CT, et al. Autonomic dysfunction in unaffected first-degree relatives of patients suffering from schizophrenia. Schizophr Bull (2010) 36:1050-8. doi:10.1093/schbul/ sbp024

14. Berger S, Boettger MK, Tancer M, Guinjoan SM, Yeragani VK, Bar KJ. Reduced cardio-respiratory coupling indicates suppression of vagal activity in healthy relatives of patients with schizophrenia. Prog Neuropsychopharmacol Biol Psychiatry (2010) 34:406-11. doi:10.1016/j.pnpbp.2010.01.009

15. Bär KJ, Letzsch A, Jochum T, Wagner G, Greiner W, Sauer H. Loss of efferent vagal activity in acute schizophrenia. J Psychiatr Res (2005) 39:519-27. doi:10.1016/j.jpsychires.2004.12.007

16. Bär KJ, Boettger MK, Koschke M, Schulz S, Chokka P, Yeragani VK, et al. Nonlinear complexity measures of heart rate variability in acute schizophrenia. Clin Neurophysiol (2007) 118:2009-15. doi:10.1016/j.clinph.2007.06.012

17. Bär KJ, Rachow T, Schulz S, Bassarab K, Haufe S, Berger S, et al. The phrenic component of acute schizophrenia - a name and its physiological reality. PLoS One (2012) 7:e33459. doi:10.1371/journal.pone.0033459
18. Bär KJ, Koschke M, Böttger MK, Berger S, Kabisch A, Sauer H, et al. Acute psychosis leads to increased QT variability in patients suffering from schizophrenia. Schizophr Res (2007) 95:115-23. doi:10.1016/j.schres.2007.05.034

19. Ostermann S, Herbsleb M, Schulz S, Donath L, Berger S, Eisenträger D, et al. Exercise reveals the interrelation of physical fitness, inflammatory response, psychopathology, and autonomic function in patients with schizophrenia. Schizophr Bull (2013) 39:1139-49. doi:10.1093/schbul/sbs085

20. Heggelund J, Hoff J, Helgerud J, Nilsberg GE, Morken G. Reduced peak oxygen uptake and implications for cardiovascular health and quality of life in patients with schizophrenia. BMC Psychiatry (2011) 11:188. doi:10.1186/1471-244X11- 188

21. Rognmo O, Hetland E, Helgerud J, Hoff J, Slordahl SA. High intensity aerobic interval exercise is superior to moderate intensity exercise for increasing aerobic capacity in patients with coronary artery disease. Eur J Cardiovasc Prev Rehabil (2004) 11:216-22. doi:10.1097/01.hjr.0000131677.96762.0c

22. Heggelund J, Nilsberg GE, Hoff J, Morken G, Helgerud J. Effects of high aerobic intensity training in patients with schizophrenia: a controlled trial. Nord J Psychiatry (2011) 65:269-75. doi:10.3109/08039488.2011.560278

23. Scheewe TW, Takken T, Kahn RS, Cahn W, Backx FJ. Effects of exercise therapy on cardiorespiratory fitness in patients with schizophrenia. Med Sci Sports Exerc (2012) 44:1834-42. doi:10.1249/MSS.0b013e318258e120

24. Scheewe TW, Backx FJ, Takken T, Jorg F, Van Strater AC, Kroes AG, et al. Exercise therapy improves mental and physical health in schizophrenia: a randomised controlled trial. Acta Psychiatr Scand (2013) 127:464-73. doi:10.1111/ acps. 12029

25. Gorczynski P, Faulkner G. Exercise therapy for schizophrenia. Cochrane Database Syst Rev (2010) 5:CD004412. doi:10.1002/14651858.CD004412.pub2

26. Blomqvist CG, Saltin B. Cardiovascular adaptations to physical training. Annu Rev Physiol (1983) 45:169-89. doi:10.1146/annurev.ph.45.030183.001125

27. Smith ML, Hudson DL, Graitzer HM, Raven PB. Exercise training bradycardia: the role of autonomic balance. Med Sci Sports Exerc (1989) 21:40-4. doi:10.1249/00005768-198902000-00008

28. Dixon EM, Kamath MV, Mccartney N, Fallen EL. Neural regulation of heart rate variability in endurance athletes and sedentary controls. Cardiovasc Res (1992) 26:713-9. doi:10.1093/cvr/26.7.713

29. Goldsmith RL, Bigger JT Jr, Steinman RC, Fleiss JL. Comparison of 24-hour parasympathetic activity in endurance-trained and untrained young men. J Am Coll Cardiol (1992) 20:552-8. doi:10.1016/0735-1097(92)90007-A

30. Shin K, Minamitani H, Onishi S, Yamazaki H, Lee M. Autonomic differences between athletes and nonathletes: spectral analysis approach. Med Sci Sports Exerc (1997) 29:1482-90. doi:10.1097/00005768-199711000-00015

31. Melanson EL, Freedson PS. The effect of endurance training on resting heart rate variability in sedentary adult males. Eur J Appl Physiol (2001) 85:442-9. doi:10.1007/s004210100479

32. Yamamoto K, Miyachi M, Saitoh T, Yoshioka A, Onodera S. Effects of endurance training on resting and post-exercise cardiac autonomic control. Med Sci Sports Exerc (2001) 33:1496-502. doi:10.1097/00005768-200109000-00012

33. Tulppo MP, Hautala AJ, Makikallio TH, Laukkanen RT, Nissila S, Hughson RL, et al. Effects of aerobic training on heart rate dynamics in sedentary subjects. J Appl Physiol (1985) (2003) 95:364-72. doi:10.1152/japplphysiol.00751.2002

34. Carter JB, Banister EW, Blaber AP. The effect of age and gender on heart rate variability after endurance training. Med Sci Sports Exerc (2003) 35:1333-40. doi:10.1249/01.MSS.0000079046.01763.8F

35. Leicht AS, Allen GD, Hoey AJ. Influence of intensive cycling training on heart rate variability during rest and exercise. Can J Appl Physiol (2003) 28:898-909. doi:10.1139/h03-033

36. Pecanha T, De Paula-Ribeiro M, Nasario-Junior O, De Lima JR. Post-exercise heart rate variability recovery: a time-frequency analysis. Acta Cardiol (2013) 68:607-13. doi:10.1007/s00421-007-0594-5

37. Aubert AE, Seps B, Beckers F. Heart rate variability in athletes. Sports Med (2003) 33:889-919. doi:10.2165/00007256-200333120-00003

38. Kaikkonen P, Rusko H, Martinmaki K. Post-exercise heart rate variability of endurance athletes after different high-intensity exercise interventions. Scand J Med Sci Sports (2008) 18:511-9. doi:10.1111/j.1600-0838.2007. 00728.x

39. Cornelissen VA, Verheyden B, Aubert AE, Fagard RH. Effects of aerobic training intensity on resting, exercise and post-exercise blood pressure, heart rate and heart-rate variability. J Hum Hypertens (2010) 24:175-82. doi:10.1038/jhh. 2009.51 
40. Helgerud J, Hoydal K, Wang E, Karlsen T, Berg P, Bjerkaas M, et al. Aerobic high-intensity intervals improve VO2max more than moderate training. Med Sci Sports Exerc (2007) 39:665-71. doi:10.1249/mss.0b013e3180304570

41. Kay SR, Fiszbein A, Opler LA. The positive and negative syndrome scale (PANSS) for schizophrenia. Schizophr Bull (1987) 13:261-76. doi:10.1093/ schbul/13.2.261

42. ACSM. ACSM's Resource Manual for Guidelines for Exercise Testing and Prescription. Baltimore, PA: Lippincott Williams \& Wilkins (2010).

43. Durnin JV, Womersley J. Body fat assessed from total body density and its estimation from skinfold thickness: measurements on 481 men and women aged from 16 to 72 years. Br J Nutr (1974) 32:77-97. doi:10.1079/ BJN19740060

44. Siri WE. Body composition from fluid spaces and density: analysis of methods. In: Brozek J, Honschel A, editors. Techniques for Measuring Body Composition. Washington, DC: National Academy of Sciences/National Research Council (1961). p. 223-44.

45. Kligfield P, Gettes LS, Bailey JJ, Childers R, Deal BJ, Hancock EW, et al. Recommendations for the standardization and interpretation of the electrocardiogram. Part I: the electrocardiogram and its technology. A scientific statement from the American Heart Association Electrocardiography and Arrhythmias Committee, Council on Clinical Cardiology; the American College of Cardiology Foundation; and the Heart Rhythm Society. Heart Rhythm (2007) 4:394-412. doi:10.1016/j.hrthm.2007.01.027

46. Kamen PW, Krum H, Tonkin AM. Poincare plot of heart rate variability allows quantitative display of parasympathetic nervous activity in humans. Clin Sci (Lond) (1996) 91:201-8.

47. Mourot L, Bouhaddi M, Perrey S, Rouillon JD, Regnard J. Quantitative Poincare plot analysis of heart rate variability: effect of endurance training. Eur J Appl Physiol (2004) 91:79-87. doi:10.1007/s00421-003-0917-0

48. Robergs RA, Dwyer D, Astorino T. Recommendations for improved data processing from expired gas analysis indirect calorimetry. Sports Med (2010) 40:95-111. doi:10.2165/11319670-000000000-00000

49. Beaver WL, Wasserman K, Whipp BJ. A new method for detecting anaerobic threshold by gas exchange. J Appl Physiol (1986) 60:2020-7.

50. Myers J, Prakash M, Froelicher V, Do D, Partington S, Atwood JE. Exercise capacity and mortality among men referred for exercise testing. N Engl J Med (2002) 346:793-801. doi:10.1056/NEJMoa011858

51. Kodama S, Saito K, Tanaka S, Maki M, Yachi Y, Asumi M, et al. Cardiorespiratory fitness as a quantitative predictor of all-cause mortality and cardiovascular events in healthy men and women: a meta-analysis. JAMA (2009) 301:2024-35. doi:10.1001/jama.2009.681

52. Aspenes ST, Nilsen TI, Skaug EA, Bertheussen GF, Ellingsen O, Vatten L, et al. Peak oxygen uptake and cardiovascular risk factors in 4631 healthy women and men. Med Sci Sports Exerc (2011) 43:1465-73. doi:10.1249/MSS. 0b013e31820ca81c
53. Strassnig M, Brar JS, Ganguli R. Low cardiorespiratory fitness and physical functional capacity in obese patients with schizophrenia. Schizophr Res (2011) 126:103-9. doi:10.1016/j.schres.2010.10.025

54. Gretchen-Doorly D, Kite RE, Subotnik KL, Detore NR, Ventura J, Kurtz AS, et al Cardiorespiratory endurance, muscular flexibility and strength in first-episode schizophrenia patients: use of a standardized fitness assessment. Early Interv Psychiatry (2012) 6:185-90. doi:10.1111/j.1751-7893.2011.00313.x

55. Brown S, Birtwistle J, Roe L, Thompson C. The unhealthy lifestyle of people with schizophrenia. Psychol Med (1999) 29:697-701. doi:10.1017/ S0033291798008186

56. McCreadie RG, Kelly C, Connolly M, Williams S, Baxter G, Lean M, et al. Dietary improvement in people with schizophrenia: randomised controlled trial. $\mathrm{Br}$ J Psychiatry (2005) 187:346-51. doi:10.1192/bjp.187.4.346

57. Pate RR, Pratt M, Blair SN, Haskell WL, Macera CA, Bouchard C, et al. Physical activity and public health. A recommendation from the centers for disease control and prevention and the American college of sports medicine. JAMA (1995) 273:402-7. doi:10.1001/jama.273.5.402

58. Duraiswamy G, Thirthalli J, Nagendra HR, Gangadhar BN. Yoga therapy as an add-on treatment in the management of patients with schizophrenia - a randomized controlled trial. Acta Psychiatr Scand (2007) 116:226-32. doi:10.1111/j.1600-0447.2007.01032.x

59. Vancampfort D, Vansteelandt K, Scheewe T, Probst M, Knapen J, De Herdt A, et al. Yoga in schizophrenia: a systematic review of randomised controlled trials. Acta Psychiatr Scand (2012) 126:12-20. doi:10.1111/j.1600-0447.2012.01865.x

60. Peupelmann J, Boettger MK, Ruhland C, Berger S, Ramachandraiah CT, Yeragani VK, et al. Cardio-respiratory coupling indicates suppression of vagal activity in acute schizophrenia. Schizophr Res (2009) 112:153-7. doi:10.1016/j.schres.2009. 03.042

Conflict of Interest Statement: The authors declare that the research was conducted in the absence of any commercial or financial relationships that could be construed as a potential conflict of interest.

Received: 05 May 2014; accepted: 14 August 2014; published online: 29 August 2014. Citation: Herbsleb M, Mühlhaus T and Bär K-J (2014) Differential cardiac effects of aerobic interval training versus moderate continuous training in a patient with schizophrenia: a case report. Front. Psychiatry 5:119. doi: 10.3389/fpsyt.2014.00119 This article was submitted to Schizophrenia, a section of the journal Frontiers in Psychiatry.

Copyright (C) 2014 Herbsleb, Mühlhaus and Bär. This is an open-access article distributed under the terms of the Creative Commons Attribution License (CC BY). The use, distribution or reproduction in other forums is permitted, provided the original author(s) orlicensor are credited and that the original publication in this journal is cited, in accordance with accepted academic practice. No use, distribution or reproduction is permitted which does not comply with these terms. 